\title{
DIAGNÓSTICO Y PERSPECTIVAS DE LA ECONOMÍA PERUANA Y POLÍTICAS PARA SALIR DEL ENTRAMPAMIENTO ESTRUCTURAL
}

\author{
Econ. Nicko Gomero Gonzales*
}

\begin{abstract}
RESUMEN
A continuación se hace un diagnóstico de la economía peruana, en donde se pone al descubierto la ineficacia de los modelos económicos implementados desde 1985, incluido el actual gobierno que aún no logra encontrar un norte económico claro que guie a los agentes económicos, en especial a las empresas, cuyas debilidades siguen latentes, cuando justamente se necesita el desarrollo de fortalezas para competir en este mundo globalizado. En este sentido el escenario social continúa deteriorándose, el desempleo y la pobreza se han convertido en un mal endémico, cuyos efectos colaterales se convierten en elementos que podrían comprometer los regímenes de gobierno. Por ello se plantean políticas alternativas de desarrollo, que podrían resolver los problemas estructurales que aquejan a la economía y la sociedad.
\end{abstract}

\section{LA ECONOMÍA PERUANA EN LOS ÚLTIMOS QUINCE AÑOS}

\section{La Heterodoxia Económica: 1985-1990}

Quizá una de las gestiones económicas más controvertidas que uno pueda recordar es aquella que se desarrolló durante los años 1985-1990, específicamente en el gobierno aprista que, apoyado bajo la Heterodoxia, modelo de centro izquierda, diseñó medidas que llevó al país a la bancarrota económica.

En el campo real se apostó por el control de precios y la regulación del comercio a través de aranceles que no permitían una sana competencia. Y lo más grave, se mantenía en cartera una serie de empresas del Estado cuyo déficit financiero empujaba a un desequilibrio fiscal insostenible.

Bajo el supuesto de tener un mayor margen de maniobra en el campo interno, pensando reactivar la demanda agregada y con ello el aparato productivo, fijó una tasa de cumplimiento financiero para el pago del servicio de la deuda externa, el cual llegó al 10\% de las exportaciones; esta medida significó el rompimiento con los principales organismos financieros internacionales.

Ante las brechas fiscales existentes, la emisión de la moneda estaba al orden del día, crecía por encima a la inflación hasta que se llegó al límite de más de los $7400 \%$, que fue la detonante para la total ingobernabilidad económica y social.

En el campo financiero las tasas de interés estaban controladas y eran marcadamente negativas; existía un sistema cambiario múltiple llegando a existir hasta diez tipos de cambio en 1987; las operaciones financieras del Banco Central eran selectivas y subsidiadas; existían elevadas tasas de encaje, las divisas eran asignadas por el Banco Central según el tipo de importación.

* Profesor Auxiliar de la Facultad de Ciencias Contables 
Es más, en este período, la economía peruana atravesó por un fuerte proceso de desintermediación financiera, reduciéndose sustancialmente la demanda por saldos monetarios reales con el marcado resurgimiento de los mercados financieros informales y de la dolarización de la economía.

En 1990 el valor real del dinero y cuasidinero llegó apenas al $19 \%$ del registrado en 1985 y el crédito bancario al sector privado se redujo al $15 \%$ del que había en 1985. El Banco Central fue manejado más como un banco de fomento cuya función se enmarcaba en el financiamiento sistemático de los déficit fiscales. Otorgaba préstamos al Gobierno Central que prácticamente no devengaban intereses y que rápidamente perdieron su valor real por la creciente inflación, generándose perdidas considerables a las cuentas de la Autoridad Monetaria.

Al final de la gestión aprista no se tenía reservas internacionales, se quebró el aparato productivo y se agudizó la pobreza extrema, lo cual constantemente era aprovechado por los grupos violentistas para desequilibrar aun más el escenario social. Se proyectó así al exterior una pésima señal de ingobernabilidad, lo cual como es obvio, perjudicó el flujo de capitales hacia este mercado. En resumen, fracasó la heterodoxia económica como modelo de gestión económica, profundizando con ello los problemas estructurales del país.

\section{La Economía en los Noventa: El Liberalismo}

A partir de agosto de 1990 el gobierno de Fujimori, bajo el marco de una economía de mercado, adopta un programa de estabilización y de reformas estructurales que para muchos analistas económicos más se acercaba a la ortodoxia económica; es decir, aquel modelo económico cuya filosofía está centrada en el mercado como el mejor asignador de recursos.
Con respecto a la estabilización, la meta principal fue eliminar la hiperinflación por medio de una estricta política fiscal y monetaria. Esto implicó la eliminación de subsidios generalizados, reformas tributarias, control estricto del gasto público, racionalización de las empresas públicas antes de su privatización y un control disciplinado de la emisión monetaria.

El proceso de estabilización fue acompañado por importantes reformas estructurales y un amplio programa de privatización. Se eliminaron todas las restricciones cuantitativas de comercio exterior, se redujeron y uniformizaron los aranceles, se redujo el arancel promedio del $60 \%$ al $16 \%$, se permitió la libre entrada y salida de capitales del país, se eliminó el diferencial de tasas de cambio, se redujo el tamaño del sector público, se privatizó las Empresas del Estado con problemas financieros, se flexibilizó el mercado laboral, y se implementaron otras medidas que apuntaban a sanear lo dejado por el gobierno aprista.

Con respecto a la reinserción del Perú a la economía mundial, se fueron eliminando los atrasos de pago con los organismos internacionales, se refinanció la deuda con los acreedores del Club de París, se llevó a cabo conversaciones con la banca internacional para obtener una solución a largo plazo respecto a los atrasos de la deuda, lo cual permitió una fuerte reanudación de la actividad crediticia de los organismos internacionales $y$ otras instituciones oficiales extranjeras.

En este mismo campo algunas empresas peruanas retornaron a los mercados internacionales no sólo para obtener financiamiento de corto plazo, sino también de mediano y largo plazo y, como es obvio, se dinamizó el mercado bursátil, que por esos años, logró alcanzar las más altas tasas de rentabilidad a nivel de la región.

Con el ahorro externo, captado en el extranjero, se abrieron los créditos a las 
empresas nacionales, apalancamiento que sirvió para financiar sus capitales de trabajo $e$ inversión a tasas de interés preferenciales, apoyo financiero que no sólo llegó a la mediana y gran empresa sino también a la micreompresa, que en estos últimos tiempos se ha convertido en el principal amortiguador del desempleo.

El tipo de cambio nunca más fue fijado por el BCR, sino que el mercado jugó su papel en la cotización de la divisa; aquí el ente emisor actuaba como un componente o agente más del mercado, que en cierta forma actuó como instrumento dinamizador de las exportaciones.

\section{Resultados del modelo}

El PBI de 1993 a 1997 alcanzó un crecimiento acumulado de $41.9 \%$ hecho que permitió que seamos los primeros en crecer a nivel de Latinoamérica; no sólo se creció, sino que uno de los factores más perniciosos de la economía llamado inflación comenzó a bajar paulatinamente hasta llegar a un crecimiento de precios anual del $4.1 \%$, porcentaje sólo comparable con los países más industrializados.

Al observar los inversionistas internacionales que la economía peruana, producto de aplicación del modelo económico social de mercado, estaba completamente estabilizada y crecía sostenidamente desviaron sus capitales a este mercado para colocarlos en los diferentes sectores productivos reales, financieros, y de servicios. Empresarios chilenos, españoles, del Reino Unido, entre otros, acumularon inversiones por 7340.6 millones de dólares, que dieron verdadero impulso para el logro del crecimiento sostenido.

Como se sabe, la estructura legal de fomento a la inversión privada se basó en el DL 662, ley de Promoción de la Inversión Extranjera y el DL 752, ley marco para el crecimiento de la inversión privada en el proceso de privatización. Esta normatividad apoyaba a la inversión privada en el país estableciéndose un régimen de protección y garantía a los flujos de capital, materializado con la suscripción de Convenios de Estabilidad Jurídica; asimismo se suscribió convenios constitutivos de la Agencia Multilateral para la Garantía de las Inversiones (MIGA) del Banco Mundial.

Con el objetivo de fomentar el desarrollo de grandes proyectos de exploración y explotación de recursos naturales el Gobierno puso en práctica un mecanismo fiscal que permitió, en el caso de proyectos de larga maduración, recuperar de manera anticipada el impuesto pagado por las operaciones de importación, y adquisición de bienes intermedios, bienes de capital y contratos de construcción que se utilicen directamente en la ejecución del proyecto.

En el escenario de inversión es importante tocar el proyecto minero Antamina, el cual representaría un desembolso de 2 mil millones de dólares, con un efecto multiplicador en las exportaciones por 700 millones de dólares, y en la creación de 4000 puestos de trabajo en la etapa de construcción.

Al tener una producción creciente, como producto de las inversiones, el saldo exportable fue en aumento $y$ con ello las exportaciones; éstas se multiplicaron por tres hasta llegar cerca de los 8000 millones de dólares. Con el impacto positivo en las RIN que desbordaron los 10 mil millones de dólares, colchón financiero que garantizaba el modelo de estabilización y proyectaba tranquilidad a los agentes económicos, siendo la mejor señal de este fenómeno la extinción de las expectativas especulativas en los mercados.

Por otro lado, la reinserción al mercado financiero internacional abrió el caño a los capitales de las instituciones financieras internacionales, el FMI como el Banco Mundial (BM) desembolsaron capitales de largo plazo y blandos por 1500 millones de 
dólares dirigidos a fortalecer nuestra infraestructura económica.

Con estos efectos en la economía los ingresos reales lograron recuperarse, con un sol más fuerte, el poder de compra fue en aumento, que se reflejó en el dinamismo de la demanda agregada, que por el efecto arrastre también el sector productivo lo hizo en la misma dirección.

A pesar de estos «logros macroeconómicos», que mereció la aprobación de los organismos financieros internacionales, de las calificadoras de riesgo, (Mody'sEstándar \& Poor's- Morgan Stanley), el modelo económico tan igual como el heterodoxo, no logró eliminar los problemas estructurales que aún persisten; si bien es cierto que en esos años no se hicieron explícitos los descontentos sociales, por las efectivas campañas sicosociales y por ende de represión sicológica del gobierno a la población; peligrosamente se fueron embalsando hasta crearse un escenario de grave conflicto aún subterráneo que puede hacer peligrar el orden constitucional.

El modelo ortodoxo liberal también tuvo sus limitaciones, el desempleo creció, la economía subterránea se fortaleció, la extrema pobreza traspasó las capas sociales tradicionales, la economía terminó paralizada, muchas empresas quebraron por incompetencia; es decir el país, en términos macroeconómicos y microeconómicos entró en una franco deterioro, inclusive moral, por la corrupción, consolidándose así, como ya se expresó líneas arriba, el fracaso de la ortodoxia económica.

\section{MODELO ECONÓMICO BAJO EL GOBIERNO DE TOLEDO}

El gobierno del presidente Toledo asumió un país bajo estas características; recesado, con elevados signos de corrupción, pero "estabilizado" relativamente en las cuentas macroeconómicas (inflación, devaluación).
Si el gobierno de los noventa manejó la política económica bajo el marco de la ortodoxia económica, el gobierno actual, sustancialmente, viene utilizando las mismas estrategias de tipo monetario como fiscal para mantener estabilizado el escenario macroeconómico. Si bien se ha logrado este propósito, ya que la inflación como la devaluación están controladas; pero no se ha conseguido revertir los problemas estructurales: lo cual es lo mismo decir que la sociedad sigue más debilitada y con menos capacidad para competir en este mundo globalizado.

Pero hay que señalar que la gestión económica no sólo debe involucrar la manipulación de instrumentos para mantener estabilizada la economía, sino también es necesario que se active los mecanismos necesarios para realizar las reformas estructurales cosa que la actual administración no ha dado señales de efectivizar. Si bien es cierto que el escenario social ha creado barreras que impiden emprender políticas de esta naturaleza, especialmente en el campo de la privatización, y el achicamiento del Estado, pero es necesario que los gestores económicos ensayen formulas novedosas para fortalecer la cadena de reformas necesarias para potenciar la economía en forma sostenida.

No hay duda que erradicar la corrupción enquistada en los últimos años, es de imperiosa necesidad para salir del estado de postración económica y social, pero hay que entender que la agenda de gobierno no sólo debe estar ocupada por estos temas, sino que es necesario emprender políticas claras, serias, coherentes e inteligentes para minimizar los indicadores derivados de la pobreza y el desempleo, cosa que el Ejecutivo como Legislativo han demostrado que no dan muestras de visión para lograr su solución.

El crecimiento del PBI en estos últimos meses se ha debido más que todo a la 
maduración de los grandes proyectos mineros, que como se conoce, no generan valor agregado, y a un cierto rebote técnico; mas no así a las políticas sectoriales, que como afirman analistas especializados en el tema, han sido poco eficaces y con ello, como es obvio, se siguen agravando los problemas sociales que han comprometido la estabilidad del gobierno. Nuevamente, el modelo económico, operativizado bajo un sistema político «democrático», viene dando señales de debilidades más que de fortalezas.

\section{¿LA HETERODOXIA Y LA ORTODOXIA SON SUFICIENTES PARA SOWUCIONAR LOS PROBLEMAS ECONÓMICOS Y SOCIALES?}

Las evidencias empíricas demuestran que los modelos económicos ensayados por los dos últimos gobiernos, incluido el actual, no han logrado revertir los problemas estructurales basados en el desempleo la pobreza y sus derivados. La heterodoxia del APRA nos llevó a la peor hiperinflación de nuestra historia; la ortodoxia de Fujimori, contaminado por la hipercorrupción en las más altas esferas de gobierno, nos condujo a un escenario recesivo y al embalsamiento del descontento social de la población. Y el actual gobierno, tan igual como los que han gobernado el país, cuyas políticas macroeconómicas están monitoreadas por el Fondo Monetario Internacional (FMI), sigue sin encontrar el camino correcto que lleve al país a un escenario de bienestar. Todo lo contrario en el interno de la economía se ha creado un escenario cuyo grado de vulnerabilidad, de no corregirse a tiempo, podría hacer peligrar el orden constitucional. Como se conoce, los modelos económicos se validan por sus resultados y si se toma en cuenta esta premisa para evaluar los implementados en el país, se puede concluir que ninguno ha dado los resultados esperados: aquí las principales señales:

- Aparato productivo incapaz de enfrentar los retos de la globalización.
- Recursos humanos y tecnología con más debilidades que fortalezas para emprender un despegue económico sobre la base de competitividad.

- Un sector exportador lejos de lograr los estándares promedio para competir en los mercados más exigentes del mundo.

Un Sector Público aletargado y paquidérmico.

- Una clase política más interesada en profundizar los indicadores del subdesarrollo que, coadyuvar a su solución.

Profundización del escenario recesivo

- Persistencia de la corrupción en las más altas esferas del gobierno.

- Agudizamiento de la pobreza: aumento de la brecha social, que es el caldo de cultivo perfecto para los grupos irregulares e insurgentes.

El desempleo y el subempleo es uno de los más altos de la región.

- Profundización de las convulsiones sociales.

Indicadores educativos públicos africanizados.

Cuasi aislamiento del mundo las inversiones no especulativas de largo plazo.

Como se puede apreciar, los resultados de la política económica van más allá de la evaluación de la inflación, el tipo de cambio, - la tasa de interés; su grado de eficacia se debe medir por los resultados estructurales que es donde el Perú tiene sus mayores deficiencias.

\section{RECOMENDACIONES PARA REARMAR EL MODELO ECONÓMICO}

\section{Sustento Doctrinario del Modelo}

El Modelo Económico debe tener como base la doctrina de la Economía Social de Mercado; apartándose por ello de la doctrina ortodoxa liberal como de la 
neopopulista, encarrilamiento que dará la opción de poner la economía al servicio del hombre y no el hombre al servicio de la economía.

Para la viabilización de un programa de este tipo se requiere un Estado pequeño, eficiente y promotor; pero no intervencionista, dejando espacios que le compete moverse al sector privado. Asimismo es imprescindible, el respeto a las normas jurídicas y a la independencia de las instituciones, como forma de transmitir confianza a los agentes económicos tanto nacionales como internacionales.

Se requiere representantes del gobierno, especialmente a nivel del Ejecutivo, con suficiente solvencia moral para proyectar credibilidad hacia la sociedad, situación que facilitaría la creación de una Alianza Estratégica con fines de gobernabilidad. El entendimiento político para la gobernabilidad debe ser con la sociedad y no con grupos políticos que entre sus filas cuentas con personajes responsables de la destrucción económica, social y moral del Perú.

Es necesario realizar un trabajo de reingeniería mental en las distintas esferas sociales. Se tiene que pensar no en un proyecto personal sino en un Proyecto Nacional; cuya visión sea la de crear un país competitivo en todos los escenarios y sin aquellas taras que son propias de toda cultura tercermundista. Por ejemplo, a nivel empresarial se debe dejar de lado el mercantilismo para dar paso, al empresario con responsabilidad social; asimismo los responsables gubernamentales deben de dejar de la lado la miopía política intencionada, que comúnmente se traduce en corrupción, para dar paso a una verdadera cultura de gobernabilidad sin intereses particulares, y la gente común y corriente debe pensar que un país es grande si es que sus ciudadanos son grandes.

\section{Algunas Medidas de Política Econó- mica bajo el Modelo Alternativo}

Aquí algunas medidas de Política Económica como sociales para revertir el escenario de entrampamiento estructural de la economía

\section{A. POLÍTCAS DE TIPO ECONÓMICAS}

1. Crear una cultura pro exportadora de productos no tradicionales aprovechando la ventaja comparativa existente en el sector agrícola. Se recomienda crear una red nacional de micro y pequeñas empresas agroindustriales con fines de exportación. Priorizar los cultivos andinos.

2. Fortalecer la creación de Microempresas, con el apoyo financiero de instituciones privadas, el tecnológico y de investigación por parte del Estado. Las universidades se pueden convertir en los centros de desarrollo de las PYMEs, es aquí donde se darían las innovaciones tecnológicas, la búsqueda de mercado, el soporte de capacitación, etc. Actividades que conllevaría a que este sector se convierta en competitiva de acuerdo a los requerimientos internacionales.

3. Convertir los recursos turísticos en productos turísticos, promocionándolos en mercados emisores internacionales de elevada potencialidad. Apuntar las estrategias hacia el mercado asiático.

4. Proyectar al exterior una imagen de estabilidad en todos los escenarios con la finalidad de atraer capitales de largo plazo y no especulativos. En este sentido es necesario fortalecer la autonomía de las instituciones y el respeto por las normas jurídicas. 
5. Utilizar los Consulados como promotores de los espacios que posee el país para poder invertir. Además de ello se deben de convertir en puntos de venta para los productos de exportación en todos los mercados internacionales. Actividad que debe ser reforzada por PROM PERÚ y otras instituciones cuya función se centra en posicionar la imagen del país.

6. Manejar la política fiscal bajo los principios de austeridad y responsabilidad, especialmente para los gastos corrientes, pero sin descuidar las inversiones sociales, especialmente aquellas que tiene elevado efecto multiplicador económico como social. Buscar la maximización de la renta pública no a través de la grabación de mayores tasas impositivas sino vía el ensanchamiento de la Base Imponible.

7. Emprender programas de privatización, pero con responsabilidad social, sopesando los intereses privados con los sociales apuntando a minimizar los efectos sociales negativos de estos programas. Buscar la maximización de la rentabilidad social de la región en donde estén localizadas las empresas que se han de privatizar.

8. Desarrollar proyectos de infraestructura económica mediante redes viales que traten de crear corredores que interconecten los centros de producción con los mercados consumidores. Infraestructura que también se podría desarrollar sobre la base de concesiones con el sector privado.

9. Desarrollar políticas fronterizas en donde se podrían desarrollar proyectos binacionales con financiamiento de capitales extranjeros no reembolsables. Estos proyectos, aparte de lograr los objetivos de empleo, producción y exportacion. podrían servir para desterrar los grupos violentistas (subversivos y narcotraficantes) que se desarrollan en esta zona.

10. Fortalecer los lazos comerciales con los demás países de la región con el fin de no sólo tranzar productos sino también tecnología y ciencia. Para este objetivo se plantea ejecutar corredores internacionales para llegar a mega mercados, como el asiático.

11. La política monetaria debe de obedecer estrictamente a los objetivos macroeconómicos y no a los propósitos políticos del gobierno de turno.

12. Minimizar los gastos operativos de la clase política gobernante para desviarlos a aquellos sectores que son de mayor prioridad para los intereses de desarrollo del país.

13. Fortalecer la inserción del Perú en el mercado financiero internacional, pero sin supeditar el accionar de nuestra economía a los parámetros que imponen los organismos internacionales, como el FMI.

14. Plantear la idea en los Forums Internacionales organizados por el FMI, BM,BID, ONU, que "no solo se debe de fortalecer la globalización económica, sino también se debe de perseguir la globalización social". Detrás de este principio está la redistribución equitativa de la riqueza mundial, el cual es el mejor antídoto para mantener estabilizada socialmente las economías de los países emergentes.

\section{B. Políticas Sociales}

1. Priorizar los gastos en Educación en todos los niveles apuntando a 
formar un ciudadano acorde al nuevo orden económico, social y político mundial.

2. Reconvertir los programas asistencialistas en programas productivos $y$ autosostenidos que representen una mínima carga fiscal para el Estado. Por ejemplo los comedores populares, club de madres, Comités de Vaso de Leche, bajo Alianza Estratégica con los Centros de Capacitación tecnológico y universitario del Estado podrían convertirse en centros de producción especializados y competitivos.

3. Las leyes laborales deben de apuntar a la competitividad y productividad, como forma de multiplicar la riqueza en el país. Manejar el principio que la estabilidad laboral depende del grado de eficacia del trabajador más no de las argucias legales fabricadas por un poder legislativo que sólo busca réditos políticos.

4. Convertir a los Centros de Educación Superior del Estado como las Instituciones pensantes, en donde se deban de desarrollar las investigaciones que se necesita para reforzar la actividad productiva del país. Asimismo, las universidades deben convertirse en los laboratorios para formular las políticas sectoriales y el gran Proyecto Nacional que es de imperiosa necesidad para el crecimiento sostenido a largo plazo del país.

5. Sanear las instituciones gubernamentales, tanto civiles como militares, de los síntomas de la corrupción estructural. Estas, por ser soporte de la actividad privada, deben de proyectar confianza, credibilidad, eficacia, es decir todos aquellos valores que coadyuven al fortalecimiento económico como social del país.

\section{CONCLUSIONES}

1. Los modelos económicos implementados en los últimos quince años, incluido la actual, no han logrado revertir los grandes problemas estructurales del país por lo que se puede afirmar que han sido estériles para mejorar el escenario económico como social.

2. Los gobiernos han confundido saneamiento económico con estabilización de la inflación, el tipo de cambio o la tasa de interés; han perdido de vista que éste no es el fin de la política económica, sino que es un medio para lograr el bienestar social integral, equilibrada de la población.

3. La redistribución de la renta sigue siendo uno de los problemas estructurales que se tiene que resolver en el corto plazo como forma de evitar las convulsiones sociales

4. El país ha estado y sigue gobernado por una clase política carente de una visión de país. Sólo se han centrado en buscar réditos políticos con el claro objetivo de perpetuarse en el poder.

5. En la década de los noventa, debido a la aplicación del modelo económico y a la débil eficacia en términos microeconomicos y sociales, se embalsó el descontento social que, actualmente por la falta de políticas claras para revertir este escenario, se puede convertir en un factor que alimente la ingobernabilidad, que inclusive podría hacer peligrar el orden constitucional.

6. Las políticas económicas ensayadas en estos últimos años no han conllevado a desarrollar un sector empresarial fuerte y competitivo; todo lo contrario, sus vulnerabilidades no garantizan que en los bloques económicos que se están formando en este mundo globalizado puedan competir con éxito lo cual agravaría la situación económica del país. 
7. Para resolver los problemas estructurales del país se tienen que ejecutar políticas sectoriales eficaces con participación de capitales extranjeros; así como políticas macroeconómicas no parametradas a las exigencias de los Organismos Financieros Internacionales, como el FMI. Pero los réditos económicos tienen que ser equilibradamente redistribuido en toda la sociedad.

\section{BIBLIOGRAFÍA}

1. Compendio Estadístico. Instituto Nacional de Estadística e Informática (INEI) Lima Perú.
2. Reseña Económica. Banco Central de Reserva BCR. Lima Perú.

3. Diario Gestión. Varios Números. Lima. Perú

4. Diario Síntesis. Varios Números. Lima Perú.

5. Concha Sequeiros Luis. La economía del Perú y los Desafíos de Futuro. Primera edición. 1998

6. Revista Comercio y Producción. 2002. Lima, Perú.

INVERSIÓNEXTRANJERA

(Millones de Dólares)

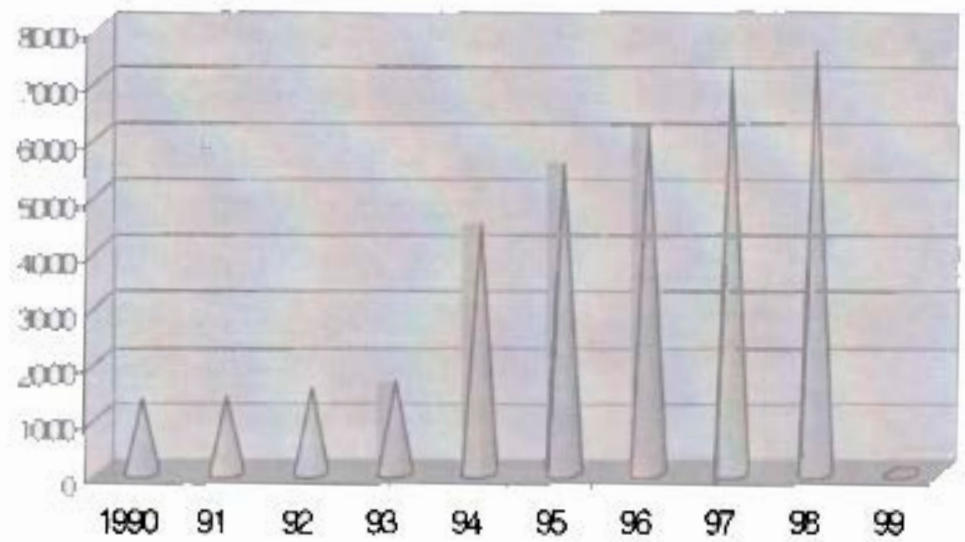

Desempleo en el Perú: 1990-1997

\begin{tabular}{lccc}
\hline Años & Desempleo abierto urbano & Desempleo Juvenil & $\begin{array}{c}\text { Desempleo en Lima } \\
\text { Metropolitana }\end{array}$ \\
\hline 1990 & 8.3 & 15.4 & 6.4 \\
1991 & 5.9 & 11.2 & 4.8 \\
1992 & 9.4 & 15.8 & 7.5 \\
1993 & 9.9 & 16.1 & 8.4 \\
1994 & 8.8 & 13.7 & 7.0 \\
1995 & 7.9 & 11.2 & 6.0 \\
1996 & 8.1 & 15.7 & 7.3 \\
1997 & 9.1 & 16.1 & 7.8 \\
\hline FUENTE: OIT & & &
\end{tabular}


INVERSION ANUAL DEL EST ADO POR

ALUMNO. Dólares del año 2000

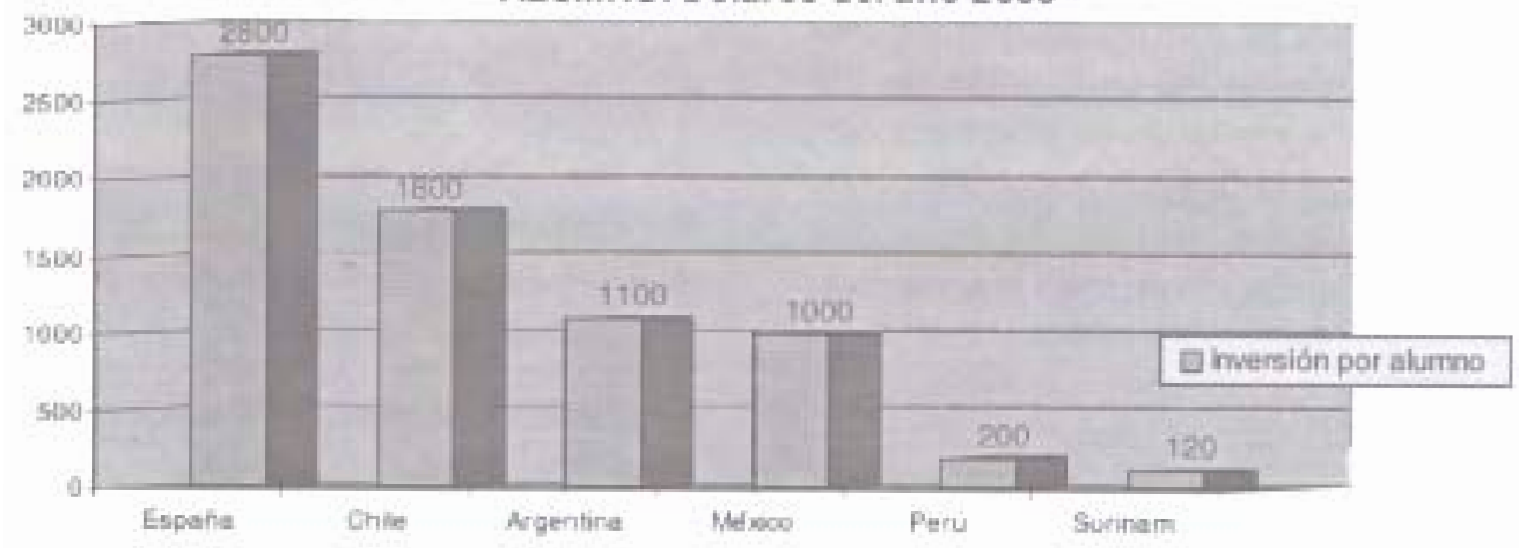

